\title{
New molecules for organic photovoltaic and solar cell applications based on N-(7-imidazolyl) -aryl sulfonamides by DFT and TD-DFT Methods
}

Siham Lakrikh ( $\nabla$ siham.lakrikh2013@gmail.com )

Universite Sultan Moulay Slimane Faculte Polydisciplinaire de Beni Mellal https://orcid.org/0000-00030325-3639

\section{Hajar Atmani}

Faculty of sciences and technologies sultan Moulay Slimane University https://orcid.org/0000-00023150-3431

\section{Latifa Laallam}

Faculty of sciences and technologies Sultan Moulay Slimane University

\section{Ahmed Jouaiti}

Faculty of sciences and technologies sultan Moulay Slimane University https://orcid.org/0000-00030587-5335

\section{Research article}

Keywords: DFT, TD-DFT, Energies LUMO and Energies HOMO and Gap, UV-Vis

Posted Date: November 18th, 2019

DOI: https://doi.org/10.21203/rs.2.17399/v1

License: (9) This work is licensed under a Creative Commons Attribution 4.0 International License. Read Full License 


\section{Abstract}

In this work, we use theoretical methods DFT density functional theory to calculate the electronic properties of the five molecules based on $\mathrm{N}$ - (7-indazolyl) -aryl sulfonamides, for an example of these parameters: $\mathrm{HOMO}$ energies, Energies of LUMO and E gap which are very interesting in the photovoltaic field. At the same time, we explore our result to achieve our goal of treminations the electronic and spectroscopic properties of these organic molecules through the use of TD-DFT, to determine the wavelengths of the molecules and to trace the visible, ultra-violet spectrum and to determine the transition states.

\section{Introduction}

Recently, the most interesting topics in materials science are materials that contain organic molecules, because these compounds become promising in all that are optoelectronic, such as phosphorescent organic light-emitting diodes (OLEDS), organic field effect transistors (OFET) [1] and organic photovoltaic (OPV) $[2,3]$.

Because of their specific properties such as the optical, electronic and photo electrochemical parameters of these compounds.

[Figure 1]

In our work, we use the DFT method on five N (7-indazole) -based C1, C2, C3, C4 and C5 molecules. We present the electronic results for finding usable organic molecules (fig 1 ) as dyes in solar cells in the photovoltaic field. In general DFT is for studying the electronic and optical properties, with a great accuracy, and less expensive than other quantum methods example MP3 AM3.

The results calculated for organic compounds obtained by the DFT method because the latter is more precise and less expensive, the DFT method has been used more widely to study the properties of organic molecules in the excited state, in this work the results calculated by DFT such as optimized geometry, structural electronic properties and photovoltaic properties such as open circuit (Voc).

\section{Method And Material}

The properties and structural descriptors of the molecules in this modest work have been calculated by the use of Gaussian software [4], using the method of density theory (DFT) with the function of the three parameters of Becke and the function of Lee Yang-Parr (B3 LYP) [5] [6] associated with 6-31 G, this method has been applied to optimize the geometry or structure of the molecule in the fundamental state, and to determine the minimum energies of the molecules, of EHOMO-ELUMO, and the Gap energies are determines. 
Electronic and photovoltaic parameters such as oscillator forces (OS) and optical transitions were calculated using the density-time functional theory (TD-DFT) combined with the 6-311G.finally to trace and to determine the ultraviolet absorption spectra of the studied molecules using GaussView software [7].

The methods used were essentially the same as in our previous work [8].

The conversion efficiency ( $\eta$ ) from sunlight to electricity in solar cell devices can be determined and calculated according to following Eq. (1) [9]:

[Due to technical limitations, the formula could not be displayed here. Please see the supplementary files section to access the formula.]

Where:

Jsc: the short-circuit current density;

Voc: the open-circuit photovoltage;

FF: the fill factor;

Pinc: the incident solar power.

Among the very important parameters in the photovoltaic domain, we will find the maximum open circuit voltage (Voc) which is calculated theoretically by the difference between $\mathrm{E}_{\mathrm{HOMO}}$ of the compounds and the $\mathrm{E}_{\mathrm{HUMO}}$ of the electron acceptor PCBM or conduction band of $\left(\mathrm{TiO}_{2}\right)$, is determined by expressions (2) $[10,11]$ :

[See supp. files]

\section{Resultants And Discussion}

\section{3-1- Electronics and photovoltaic properties}

[Figure 2]

To understand its electronic behavior we apply the analytic study of the charge distribution of the frontier orbital (FMO) of any organic molecule, in particular the separate charge between the occupied and virtual orbitals to provide reasonably qualitative indication during the process of excitation [12].

HOMOs have a non-sticking character between consecutive subunits of all compounds, whereas LUMOs show a binding character between subunits In addition, the HOMO electronic distributions are mainly located on the conjugation spacing fragment and the electron donor fragments, but in the LUMOs, the electrons are distributed mainly on the 
N- (7-indazolyl) -arylsulfonamides electron accepting units (fig 3). These electron density distributions for the test compounds are of great interest for efficient charge separation and electron injection, indicating that electron transfer will occur from the donor to the acceptor via the p-spacer therefore, electronic transitions of all HOMO dyes to LUMO could result in intramolecular charge transfer (TIC) from the electron donor to the electron acceptor unit. Here, the LUMO orbital has a considerable contribution to the N- (7indazolyl) -arylsulfonamide unit, which indicates that the coupling with the surface of the $\mathrm{TiO}_{2}$ semiconductor will be at this unit.

[Figure 3]

In the Table 1, band gap energies calculated by B3LYP/6-31. The energy gap (Egap) was evaluated theoretically as the difference between the HUMO and LOMO levels Egap = (EHOMO _ ELUMO).

On one hand, the energies of all compounds range from $2.00 \mathrm{eV}$ to $2.38 \mathrm{eV}$ in the following order: $\mathrm{C} 5<\mathrm{C} 4<\mathrm{C} 3<\mathrm{C} 2<\mathrm{C} 1$. Comparing with the $\mathrm{C} 1$ molecule, there is a destabilization of the HOMO energy and a stabilization of the LUMO energy levels.

By the use of the methyl ester of butyric acid (PCBM) or the conduction of the TiO2 bands (Fig.4), and with the LUMO energy level d of all the dyes are larger than the energy levels of PCBM (-3, $2 \mathrm{ev)} \mathrm{[13]} \mathrm{and} \mathrm{the} \mathrm{conduction} \mathrm{band} \mathrm{of} \mathrm{the} \mathrm{semiconductor} \mathrm{TiO2} \mathrm{(-4,} 0$ ev) [14]. we compare the LUMO energy levels of the compounds studied with LUMO of PCBM and the TiO2 conduction band, we find that we have a good electron injection of these dyes to acceptors PCBM and TiO2 This result indicates that it is possible to apply these compounds in the photovoltaic field and in solar cells.

And the parameter $\square_{I}$ and determine by the difference between the E LUMO levels of the studied dyes Ci and the E LUMO of the PCBM [13]:

Table 1: Electronic properties parameters (HOMO, LUMO and Egap) obtained by B3LYP/6-31G of the studied molecules $\mathrm{Ci}$.

\begin{tabular}{|c|c|c|c|}
\hline Ci & HOMO (ev) & LUMO(ev) & Egap(ev) \\
\hline C1 & -5.6044 & -2.1796 & 3.4248 \\
\hline C2 & -5.3407 & -2.0125 & 3.3282 \\
\hline C3 & -5.6292 & -1.2958 & 4.3334 \\
\hline C4 & -6.0450 & -1.3314 & 4.7136 \\
\hline C5 & -5.5067 & -2.1875 & 3.3192 \\
\hline TiO2 & & -4 & \\
\hline
\end{tabular}

[Figure 4]

Table 2: Energy values of EHOMO, ELUMO and the open circuit voltage Voc 


\begin{tabular}{|c|c|c|c|c|c|}
\hline C & HOMO(ev) & LUMO(ev) & \multicolumn{2}{|c|}{ V $_{\text {OC (ev) }}$} & \multirow{2}{*}{ (ev) } \\
\cline { 4 - 5 } & & & PCBM & TIO2 & \\
\hline C1 & -5.6044 & -2.1796 & 1.6044 & 1.4044 & 1.50204 \\
\hline C2 & -5.3407 & -2.0125 & 1.3407 & 1.1407 & 1.6875 \\
\hline C3 & -5.6292 & -1.2958 & 1.6292 & 1.4292 & 2.4042 \\
\hline C4 & -6.0450 & -1.3314 & 2.045 & 1.847 & 2.3686 \\
\hline C5 & -5.5067 & -2.1875 & 1.5067 & 1.3067 & 1.5125 \\
\hline PCBM & $-6,10$ & -3.7 & & & \\
\hline TIO2 & & -4 & & & \\
\hline
\end{tabular}

$*_{I}=$ ELUMO (Donor) _ ELUMO (PCBM); (The donor compounds are Ci).

Table 3: Data absorption spectra obtained by TD/DFT method for the compounds studied in the optimized geometries at B3LYP/6-31G. 


\begin{tabular}{|c|c|c|c|c|c|}
\hline & Electronic transitions & abs (nm) & Eex $(e V)$ & O.S (eV) & Transition (\%) \\
\hline C1 & $\begin{array}{l}\mathrm{S}_{0} \rightarrow \mathrm{S}_{1} \\
\mathrm{~S}_{0} \rightarrow \mathrm{S}_{2} \\
\mathrm{~S}_{0} \rightarrow \mathrm{S}_{3} \\
\mathrm{~S}_{0} \rightarrow \mathrm{S}_{4} \\
\mathrm{~S}_{0} \rightarrow \mathrm{S}_{5} \\
\mathrm{~S}_{0} \rightarrow \mathrm{S}_{6}\end{array}$ & $\begin{array}{l}407.12 \\
325.97 \\
311.77 \\
302.81 \\
299.15 \\
295.29\end{array}$ & $\begin{array}{c}3.0452 \\
3.8035 \\
3.9768 \\
4.0944 \\
4.1446 \\
4.41987\end{array}$ & $\begin{array}{l}0.2924 \\
0.0221 \\
0.0114 \\
0.0061 \\
0.0259 \\
0.0670\end{array}$ & $\begin{array}{ll}\text { HOMO } & \rightarrow \text { LUMO } \\
\text { HOMO-5 } & \rightarrow \text { LUMO } \\
\text { HOMO-5 } & \rightarrow \text { LUMO } \\
\text { HOMO-2 } & \rightarrow \text { LUMO } \\
\text { HOMO-5 } & \rightarrow \text { LUMO } \\
\text { HOMO-6 } & \rightarrow \text { LUMO }\end{array}$ \\
\hline $\mathrm{C} 2$ & $\begin{array}{l}\mathrm{S}_{0} \rightarrow \mathrm{S}_{1} \\
\mathrm{~S}_{0} \rightarrow \mathrm{S}_{2} \\
\mathrm{~S}_{0} \rightarrow \mathrm{S}_{3} \\
\mathrm{~S}_{0} \rightarrow \mathrm{S}_{4} \\
\mathrm{~S}_{0} \rightarrow \mathrm{S}_{5} \\
\mathrm{~S}_{0} \rightarrow \mathrm{S}_{6}\end{array}$ & $\begin{array}{l}418.8 \\
319.68 \\
315.55 \\
311.96 \\
303.44 \\
295.80\end{array}$ & $\begin{array}{l}2.9605 \\
3.8784 \\
3.9416 \\
3.9743 \\
4.0860 \\
4.1915\end{array}$ & $\begin{array}{l}0.3367 \\
0.0198 \\
0.0158 \\
0.0135 \\
0.0123 \\
0.0105\end{array}$ & $\begin{array}{l}\text { HOMO } \rightarrow \text { LUMO } \\
\text { HOMO-6 } \rightarrow \text { LUMO } \\
\text { HOMO-4 } \rightarrow \text { LUMO } \\
\text { HOMO-4 } \rightarrow \text { LUMO } \\
\text { HOMO-4 } \rightarrow \text { LUMO } \\
\text { HOMO-5 } \rightarrow \text { LUMO }\end{array}$ \\
\hline C3 & $\begin{array}{l}\mathrm{S}_{0} \rightarrow \mathrm{S}_{1} \\
\mathrm{~S}_{0} \rightarrow \mathrm{S}_{2} \\
\mathrm{~S}_{0} \rightarrow \mathrm{S}_{3} \\
\mathrm{~S}_{0} \rightarrow \mathrm{S}_{4} \\
\mathrm{~S}_{0} \rightarrow \mathrm{S}_{5} \\
\mathrm{~S}_{0} \rightarrow \mathrm{S}_{6}\end{array}$ & $\begin{array}{l}311.95 \\
289.46 \\
279.05 \\
253.24 \\
251.15 \\
241.21\end{array}$ & $\begin{array}{l}3.9745 \\
4.2833 \\
4.8959 \\
4.8959 \\
4.9366 \\
5.1400\end{array}$ & $\begin{array}{c}0.1943 \\
0.0169 \\
0.0144 \\
0.039 \\
0.0375 \\
0.0172\end{array}$ & $\begin{array}{c}\text { HOMO } \rightarrow \text { LUMO } \\
\text { HOMO } \rightarrow \text { LUMO } \\
\text { HOMO } \rightarrow \text { LUMO+2 } \\
\text { HOMO-2 } \rightarrow \text { LUMO } \\
\text { HOMO-2 } \rightarrow \text { LUMO } \\
\text { HOMO-5 } \rightarrow \text { LUMO+1 }\end{array}$ \\
\hline $\mathrm{C} 4$ & $\begin{array}{l}\mathrm{S}_{0} \rightarrow \mathrm{S}_{1} \\
\mathrm{~S}_{0} \rightarrow \mathrm{S}_{2} \\
\mathrm{~S}_{0} \rightarrow \mathrm{S}_{3} \\
\mathrm{~S}_{0} \rightarrow \mathrm{S}_{4} \\
\mathrm{~S}_{0} \rightarrow \mathrm{S}_{5} \\
\mathrm{~S}_{0} \rightarrow \mathrm{S}_{6}\end{array}$ & $\begin{array}{l}320.36 \\
288.46 \\
274.77 \\
270.91 \\
261.50 \\
258.69\end{array}$ & $\begin{array}{l}3.8701 \\
4.2981 \\
4.5123 \\
4.5766 \\
4.7412 \\
4.7928\end{array}$ & $\begin{array}{l}0.0013 \\
0.2512 \\
0.0017 \\
0.0116 \\
0.0007 \\
0.0032\end{array}$ & $\begin{array}{c}\text { HOMO } \rightarrow \text { LUMO } \\
\text { HOMO-1 } \rightarrow \text { LUMO } \\
\text { HOMO } \rightarrow \text { LUMO } \\
\text { HOMO-1 } \rightarrow \text { LUMO+1 } \\
\text { HOMO-1 } \rightarrow \text { LUMO+2 } \\
\text { HOMO-1 } \rightarrow \text { LUMO+2 }\end{array}$ \\
\hline C5 & $\begin{array}{l}\mathrm{S}_{0} \rightarrow \mathrm{S}_{1} \\
\mathrm{~S}_{0} \rightarrow \mathrm{S}_{2} \\
\mathrm{~S}_{0} \rightarrow \mathrm{S}_{3} \\
\mathrm{~S}_{0} \rightarrow \mathrm{S}_{4} \\
\mathrm{~S}_{0} \rightarrow \mathrm{S}_{5} \\
\mathrm{~S}_{0} \rightarrow \mathrm{S}_{6}\end{array}$ & $\begin{array}{l}413.27 \\
343.99 \\
333.03 \\
317.89 \\
304.61 \\
296.33\end{array}$ & $\begin{array}{l}3.0000 \\
3.6043 \\
3.7229 \\
3.9002 \\
4.0703 \\
4.1840\end{array}$ & $\begin{array}{l}0.4727 \\
0.0105 \\
0.0038 \\
0.0079 \\
0.0672 \\
0.0088\end{array}$ & $\begin{array}{c}\text { HOMO } \rightarrow \text { LUMO } \\
\text { HOMO-5 } \rightarrow \text { LUMO } \\
\text { HOMO }-2 \rightarrow \text { LUMO } \\
\text { HOMO-5 } \rightarrow \text { LUMO } \\
\text { HOMO-8 } \rightarrow \text { LUMO } \\
\text { HOMO-8 } \rightarrow \text { LUMO }\end{array}$ \\
\hline
\end{tabular}

Our objective is to determine the electronic and spectroscopic properties of $\mathrm{Ci}$ molecules by using DFT quantum chemistry calculations. After, we are interested to know influence of the parameters on the photovoltaic efficiency for a better understanding of the relations structure-property. We believe that the structural, electronic and optical properties of these compounds could help create more efficient organic materials in the functional photovoltaic field.

The HOMO and LUMO energy levels of the donor and acceptor components are very important factors in determining whether effective charge transfer will take place between 
the donor and the acceptor (Table 1). It is important to note that the LUMO levels of the compounds studied are higher than those of the conduction band of the acceptor PCBM or TiO2 (Table 2).

The theoretical values of the open circuit voltage Voc of the studied molecules range from $1.3407 \mathrm{eV}$ to $2.045 \mathrm{eV}$ in the case of PCBM (Table 2), these values being sufficient for a possible efficient injection of electrons. Therefore, all the molecules studied can be used as sensitizers because the process of electron injection of the molecule excited to the acceptor conduction band (PCBM) and the subsequent regeneration are possible in an organic sensitized solar cell. The contribution of the molecular boundary orbital (MO) is very important in the determination of the separate charge states of the studied molecules, since the relative order of the occupied and virtual orbitals provides a reasonable qualitative indication of the excitation properties as well as the capacitance. Transporting electron holes.

\section{3-2- Absorption proprieties}

[Figure 5]

The absorption of a solar cell is essential for the application of a photovoltaic material from the optimized structure from the B3LYP / 6-31G method; We calculated and plotted the UV-Vis spectra of Ci using the TD / DFT method. The simulated UV-Vis absorption spectra are identical to the previous figure (Fig 5). The values of the max converted absorption (nm) and the force of the scout (OS) as well as the configuration of the main excitation of the compounds calculated. in the following order $\mathrm{C} 2>\mathrm{C} 5>\mathrm{C} 1>\mathrm{C} 3>$ C4.

\section{Conclusion}

In this work we were interested to use the method TD-DFT / B3 LYP to study the theoretical analysis of the 5 organic molecules synthesize, we notice that:

- The UV-Vis absorption properties have been obtained by using TD/DFT calculations. The obtained absorption maximums are in the range of $311.95-418.80 \mathrm{~nm}$.

- The calculated band gap Egap of the studied molecules was in the range of 3.3192-4.7136 eV also Homo and LUMO energies.

- The calculated values of Voc of the studied molecules range from $1.3407 \mathrm{eV}$ to $2.045 \mathrm{eV}$ in the case of PCBM.

- The calculated values of Voc of the studied molecules range from $1.1429 \mathrm{eV}$ to $1.847 \mathrm{eV}$ in the case of $\mathrm{TIO} 2$.

\section{Declarations}

\section{Availability of data and materials}




\section{Acknowledgement:}

Not applicable

\section{Competing interests:}

The authors declare that they have no competing interests.

\section{Funding:}

Not applicable

\section{Authors' contributions:}

Atmani $\mathrm{H}$, Laallam $\mathrm{L}$ and Ahmed $\mathrm{A}$ contributed equally to this work

\section{Affiliations:}

Laboratory of Sustainable Development Faculty of Sciences and Technologies Sultan Moulay Slimane University B. P.523, Beni Mellal, Morocco

Lakrikh S*, Atmani H, Laallam L and Jouaiti A

\section{Reference}

[1] H. Chen, Q. Cui, G. Yu, Y. Guo, J. Huang, M. Zhu, X. Guo, Y. Liu, Synthesis and characterization of novel semiconductors based on thieno[3,2-b][1] benzothiophene cores and their applications in the organic thinfilm transistors, J. Phys. Chem. C 115 (2011) 23984-23991.

[2] H. Ebata, E. Miyazaki, T. Yamamoto, K. Takimiya, Synthesis, properties, and structures of benzo[1,2b:4,5-b0]bis[b] benzothiophene and benzo[1,2-b:4,5-b0]bis[b]benzoselenophene,Org. Lett. 9 (22) (2007) 4499-4502.

[3] J. E. Anthony, Functionalized acenes and heteroacenes for organic electronics, Chem. Rev. 106 (2006) 5028-5048.

[4] M. J. Frisch, G. W. Trucks, H. B. Schlegel, G. E. Scuseria, M. A. Robb, J. R. Cheeseman, J. A. Montgomery, T. Vreven, K. N. Kudin, J. C. Burant, J. M. Millam, S. S. Iyengar, J. Tomasi, V. Barone, B. Mennucci, M. Cossi, G. Scalmani, N. Rega, G. A. Petersson, H. Nakatsuji, M. Hada, M. Ehara, K. Toyota, R. Fukuda, J. Hasegawa, M. Ishida, T. Nakajima, Y. Honda, O. Kitao, H. Nakai, M. Klene, X. Li, J. E. Knox, H. P. 
Hratchian, J. B. Cross, V. Bakken, C. Adamo, J. Jaramillo, R. Gomperts, R. E. Stratmann, O. Yazyev, A. J. Austin, R. Cammi, C. Pomelli, J. W. Ochterski, P. Y. Ayala, K. Morokuma, G. A. Voth, P. Salvador, J. J. Dannenberg, V. G. Zakrzewski, S. Dapprich, A.D. Daniels, M. C. Strain, O. Farkas, D. K. Malick, A.D. Rabuck, K. Raghavachari, J. B. Foresman, J. V. Ortiz, Q. Cui, A. G. Baboul, S. Clifford, J. Cioslowski, B. B. Stefanov, G. Liu, A. Liashenko, P. Piskorz, I. Komaromi, R. L. Martin, D. J. Fox, T. Keith, A.M. A. Laham, C. Y. Peng, A. Nanayakkara, M. Challacombe, P.M. W. Gill, B. Johnson, W. Chen, M. W. Wong, C. Gonzalez, J. A. Pople, Gaussian 09 Revision A02, Gaussian Inc, Wallingford CT, 2009.

[5] A.D. Becke, A new mixing of Hartree-Fock and local densityfunctional theories, J. Chem. Phys. 98 (1993) 1372-1377.

[6] C. Lee, W. Yang, R. G. Parr, Development of the Colle-Salvetti correlation-energy formula into a functional of the electron density, Phys. Rev. B: Condens. Matter 37 (1988) 785.

[7] Y. Lin, H. Fan, Y. Li, X. Zhan, Thiazole-based organic semiconductors for organic electronics, Adv. Mater. 24 (23) (2012) 3087-3106.

[8] S.LAKRIKH, M. El Idrissi. “Quantitative Analysis Of The Structure-Activity Relationship Of 1, 2Benzodiazole Derivatives: DFT Study." RESEARCH JOURNAL OF PHARMACEUTICAL BIOLOGICAL AND CHEMICAL SCIENCES 9.6 (2018): 874-889.

[9] Z. Guo, W. Liang, Y. Zhao, G. Chen, Real-time propagation of the reduced one-electron density matrix in atom-centered orbitals: application to electron injection dynamics in dyesensitized TiO2 clusters, J. Phys. Chem. C 112 (42) (2008) 16655-16662.

[10] Bourass M, Benjelloun AT, Hamidi M, Benzakour M, Mcharfi M, Sfaira M, Serein-Spirau F, Lere-Porte JP, Sotiropoulos JM, Bouzzine SM, Bouachrine M. DFT theoretical investigations of r-conjugated molecules based on thienopyrazine and different acceptor moieties for organic photovoltaic cells. Journal of Saudi Chemical Society. 2016 Sep 1;20:S415-25.

[11] M. Bourass, et al., DFT / TD-DFT characterization of conjugtional electronic structures and spectral properties of materials based on thieno[3,2-b]benzothiophene for organic photovoltaic and solar cell applications,J.Saudi Chem.Soc.(2017), http://dx.doi.org/10.1016/j.jscs.2017.01.001.

[12] M. Bourass, et al., DFT and TD-DFT calculation of new thienopyrazine-based small molecules for organic solar cells, Chem. Central J. 10 (2016) 67, http://dx.doi.org/10.1186/ s13065-016-0216-6.

[13] S.Bertho,I,Haelderamans,A.Swinnen.W.Moons,T,Martens,L.Lutsen,A.Bonfiglio,Influence of thermal ageing on stability of polymer bulk heterojunction solar cells,Sol.Energy Mater.Sol.cells 91(5)(2007)385389.

[14] J. B. Asbury, Y. Q. Wang, E. Hao, H. N. Ghosh, T. Lian, Evidences of hot excited state electron injection from sensitizer molecules to TiO2 nanocrystalline thin films, Res. Chem. Intermed. 27 (4) (2001) 393- 
406.

[15] S. Bertho, I. Haeldermans, A. Swinnen, W. Moons, T. Martens, L. Lutsen, A. Bonfiglio, Influence of thermal ageing on the stability of polymer bulk heterojunction solar cells, Sol. Energy Mater. Sol. cells 91 (5) (2007) 385-389.

\section{Figures}

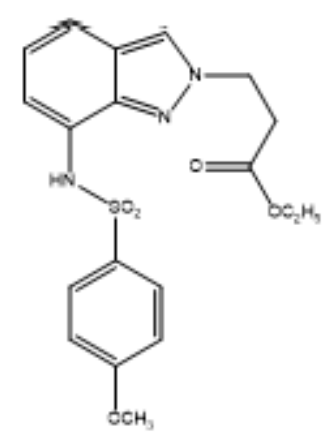

AS 2

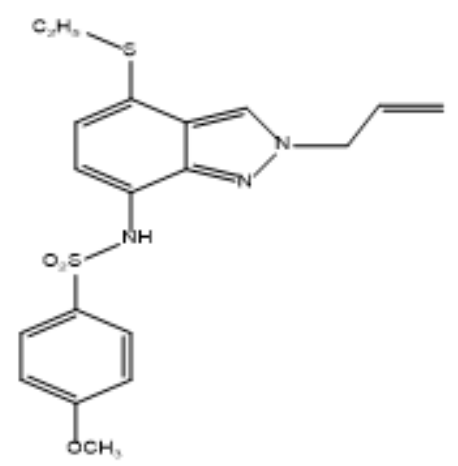

AS 15

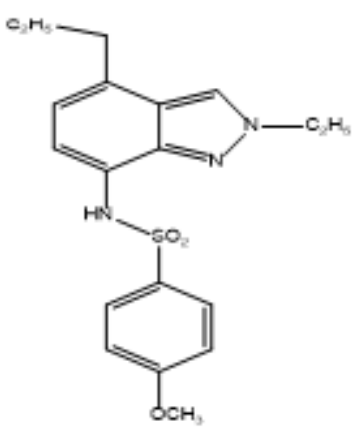

AS 3

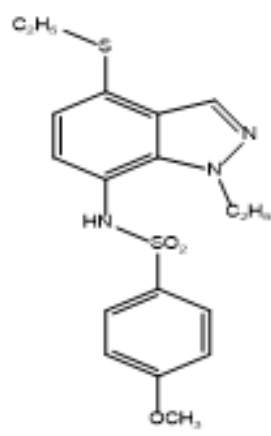

AS 19

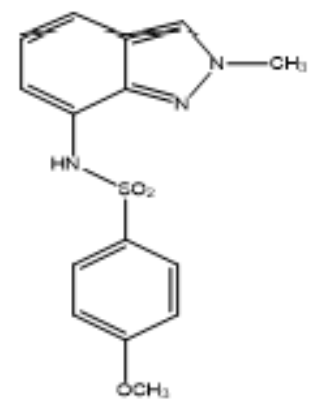

AS 6

\section{Figure 1}

Studied compounds C1, C2, C3, C4 and C5. 


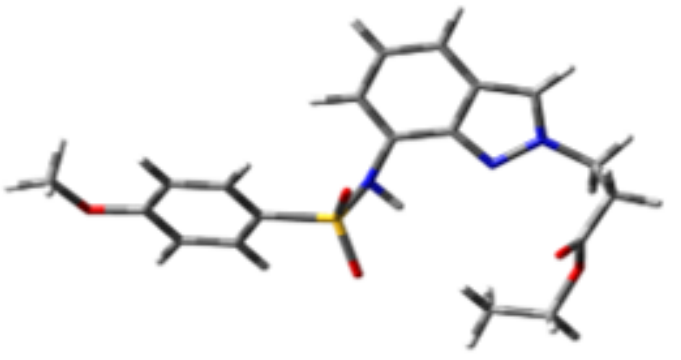

AS 2

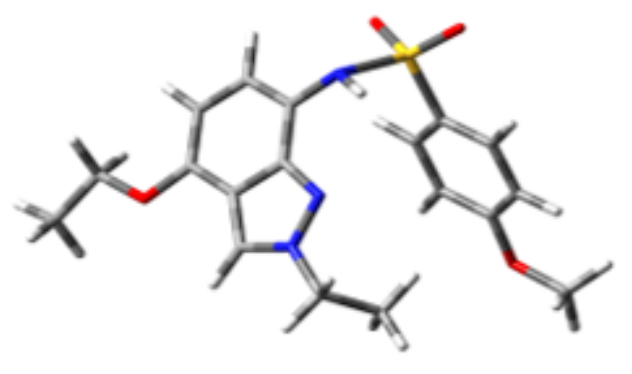

AS 6

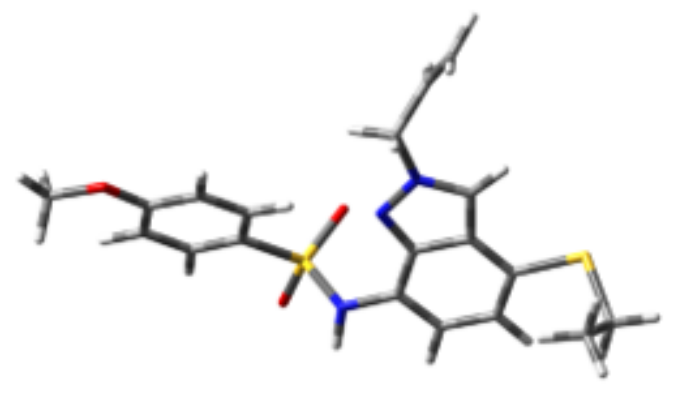

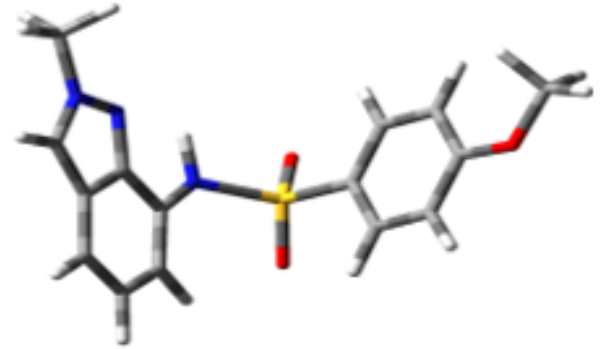

AS 3

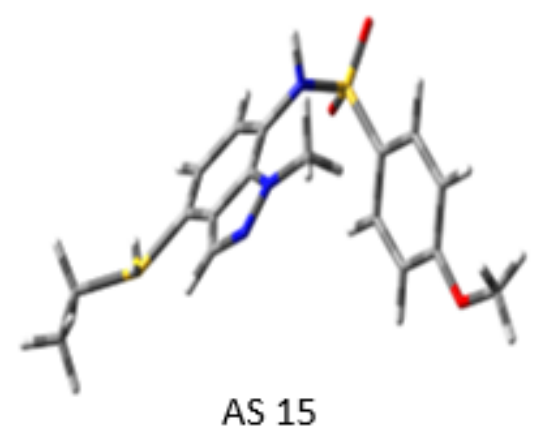

AS 15

\section{AS 19}

Figure 2

The optimized geometrical structures of the studied molecules. 
c

C1

2

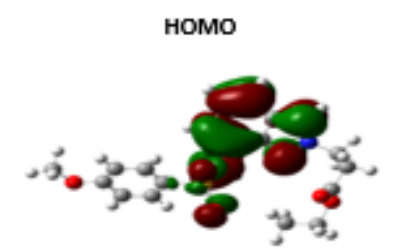

$\mathrm{C} 2$

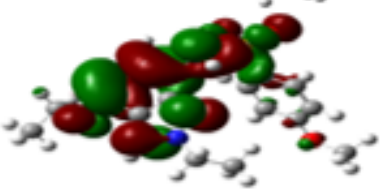

C3

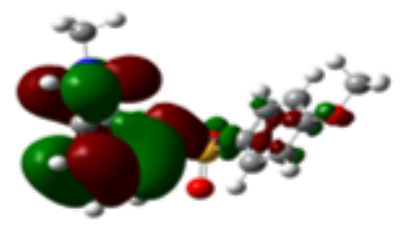

C4

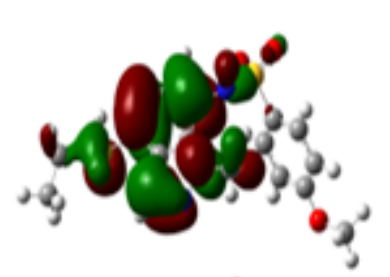

C5

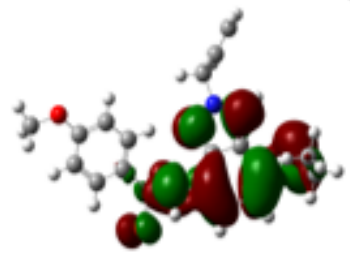

LUMo
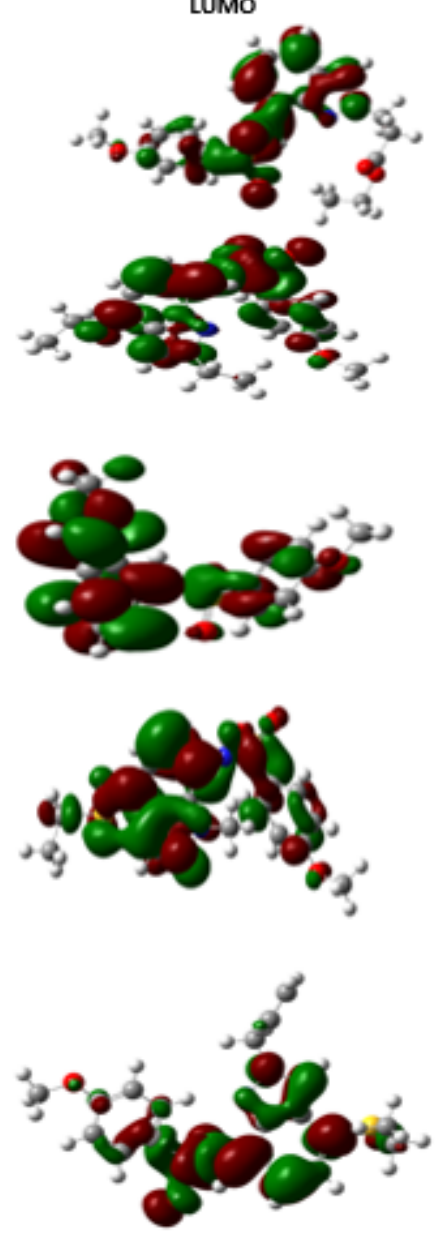

Figure 3

The contour plots of HOMO and LUMO orbitals of the studied compounds 


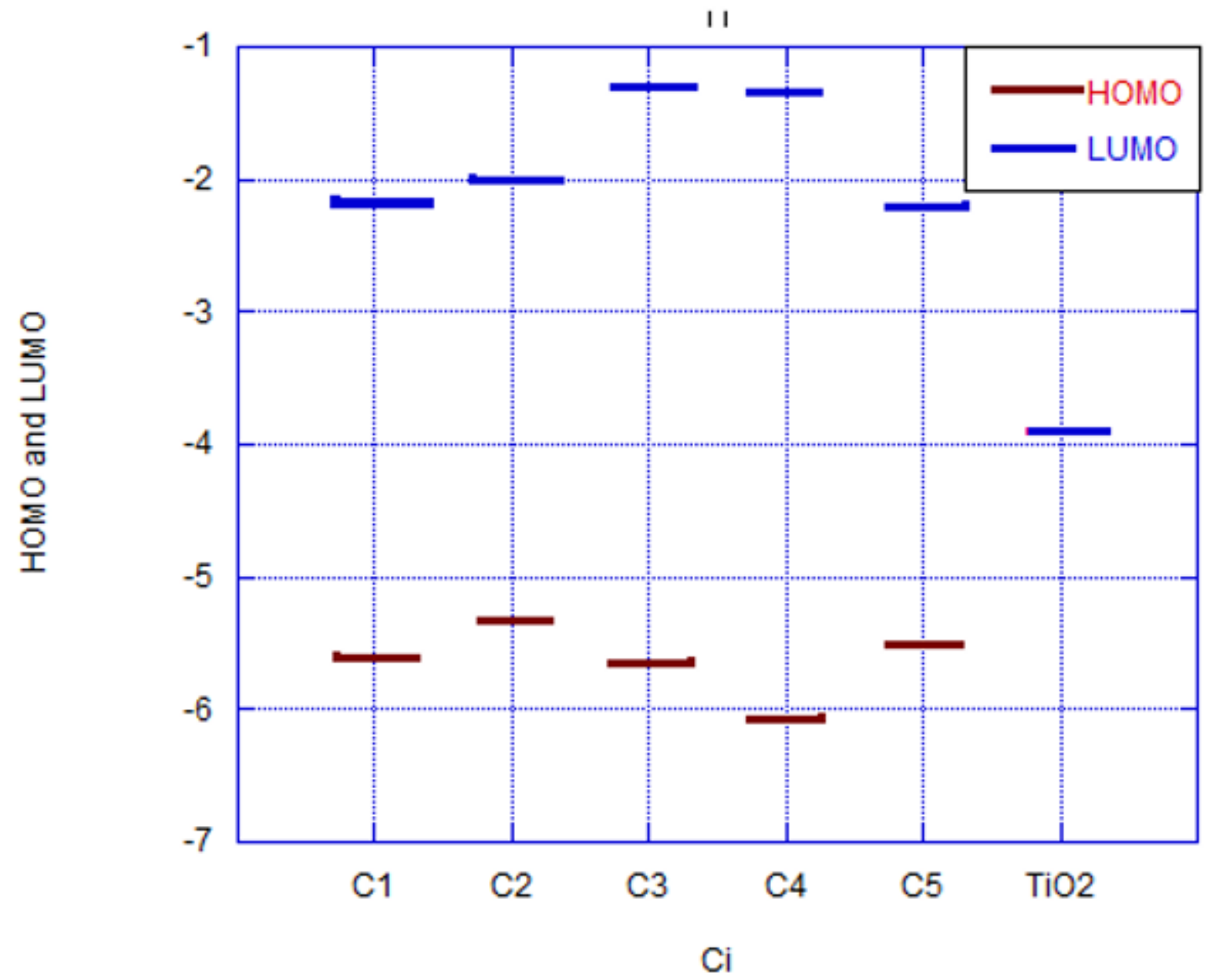

Figure 4

HOMO and LUMO of the studied compounds, ITO, TiO2 and PCBM energy levels. 


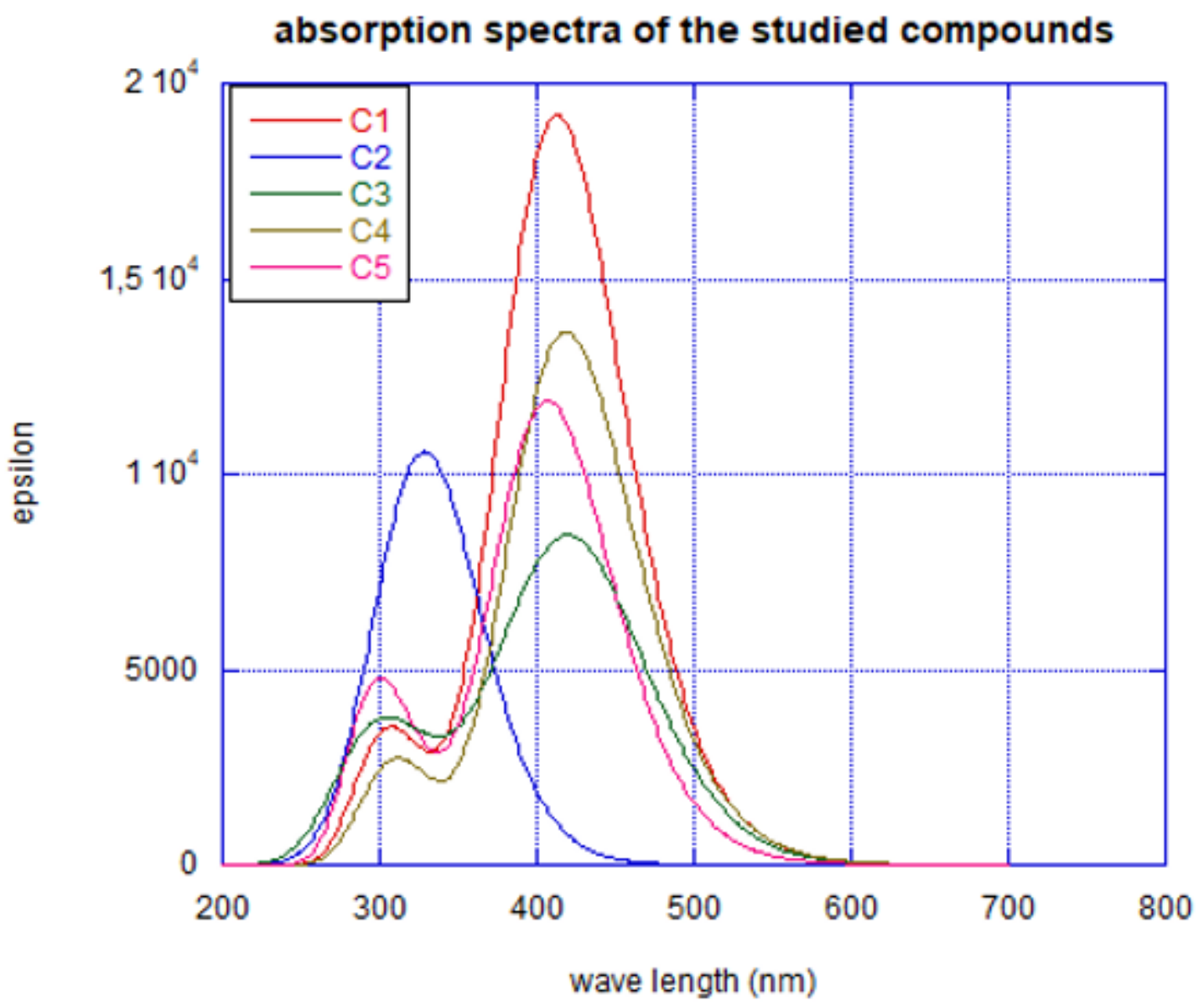

Figure 5

The absorption spectra $\prec$ max of the studied compounds

\section{Supplementary Files}

This is a list of supplementary files associated with this preprint. Click to download.

- Methodsformulas.docx 